\title{
HDAC inhibitors overcome immunotherapy resistance in B-cell lymphoma
}

\author{
Xiaoguang Wang $\mathbb{D}^{\mathbb{D}}$, Brittany C. Waschke, Rachel A Woolaver, Samantha M. Y. Chen, Zhangguo Chen, \\ Jing H. Wang ${ }^{\bowtie}$
}

Department of Immunology and Microbiology, University of Colorado Anschutz Medical Campus, School of Medicine, 12800 E. 19th Ave, Mail Stop 8333, Aurora, CO 80045, USA

$\triangle$ Correspondence: jing.wang@cuanschutz.edu (J. H. Wang)

Received December 3, 2019 Accepted January 30, 2020

\begin{abstract}
Immunotherapy has been applied successfully to treat B-cell lymphomas in preclinical models or clinical settings. However, immunotherapy resistance is a major challenge for B-cell lymphoma treatment. To overcome this issue, combinatorial therapeutic strategies have been pursued to achieve a better efficacy for treating B-cell lymphomas. One of such strategies is to combine immunotherapy with histone deacetylase (HDAC) inhibitors. HDAC inhibitors can potentially increase tumor immunogenicity, promote anti-tumor immune responses, or reverse immunosuppressive tumor environments. Thus, the combination of HDAC inhibitors and immunotherapy has drawn much attention in current cancer treatment. However, not all HDAC inhibitors are created equal and their net effects are highly dependent on the specific inhibitors used and the HDACs they target. Hence, we suggest that optimal treatment efficacy requires personalized design and rational combination based on prognostic biomarkers and unique profiles of HDAC inhibitors. Here, we discuss the possible mechanisms by which B-cell lymphomas acquire immunotherapy resistance and the effects of HDAC inhibitors on tumor cells and immune cells that could help overcome immunotherapy resistance.
\end{abstract}

KEYWORDS cancer immunotherapy, HDAC inhibitor, Bcell lymphomas, anti-PD1 resistance, tumor immunogenicity

\section{INTRODUCTION}

Non-Hodgkin lymphoma (NHL) is one of the most common type of cancers worldwide, accounting for $\sim 3 \%$ of all cancer types (Bray et al., 2018). Among NHL, B-cell lymphomas account for $>90 \%$ of cases (Scott and Gascoyne, 2014). Current treatments for B-cell lymphomas include surgery, chemotherapy, radiotherapy and immunotherapy. Taking advantage of the immune system to fight cancer, immunotherapy is a relatively newer type of cancer treatment that has the potential to be highly precise and personalized as well as more effective than other types of cancer therapies. Nowadays, immunotherapy is widely used for treating B-cell lymphomas, including antigen specific monoclonal antibodies (e.g., anti-CD20), immune checkpoint inhibitors (ICls) and chimeric antigen receptor (CAR) T cells.

The majority of B-cell lymphomas originate from germinal center (GC) or post-GC B cells, behaving like mature phenotypes (Perez-Duran et al., 2007). Within GCs, B cells undergo secondary antibody gene diversification including class switch recombination (CSR) and somatic hypermutation (SHM) (Wang, 2013; Chen and Wang, 2014). Both CSR and SHM require an enzyme called activation-induced deaminase (AID) (Muramatsu et al., 2000). B-cell lymphomas often harbor reciprocal chromosomal translocations that juxtapose the immunoglobulin $(\mathrm{lg})$ loci and proto-oncogenes (e.g., c-myc) (Wang et al., 2008; Wang et al., 2009), or mutations of non-lg genes that are targets of AID (Kuppers, 2005; Chen and Wang, 2014). In addition, various Ig-derived neoantigens were identified in multiple subtypes of B-cell lymphomas and such neoantigen presentation by major histocompatibility complex (MHC) class I and class II is a general phenomenon of B-cell malignancies (Khodadoust et al., 2017; Khodadoust et al., 2019). As a cancer type with relatively high mutation burden, B-cell lymphomas seem to be highly immunogenic and suitable for cancer immunotherapy (Yi et al., 2018). Moreover, PD-1 expression of tumor-infiltrating $\mathrm{T}$ cells is frequently increased in B-cell lymphomas, which provides a biological basis for the application of ICls (Xu-Monette et al., 2018). However, a majority 
of B-cell lymphoma patients do not benefit from ICls (e.g., anti-PD-1) (primary resistance) and others relapse after initial responses (acquired resistance) (Merryman et al., 2017; Xu-Monette et al., 2018). A better understanding of resistance mechanisms of PD-1 blockade is critical to improve the efficacy of cancer immunotherapy and to identify complementary or alternative approaches to overcome immunotherapy resistance in B-cell lymphomas. Hence, this review focuses on discussing the possible mechanisms by which B-cell lymphomas acquire immunotherapy resistance and the effects of HDAC inhibitors on tumor cells and immune cells that could help overcome immunotherapy resistance (Fig. 1).

\section{IMMUNOTHERAPY RESISTANCE BY B-CELL LYMPHOMAS}

While the primary function of $B$ cells is to produce antibodies that mediate humoral immunity, $B$ cells can also function as professional antigen-presenting cells (APCs). B cells constitutively express $\mathrm{MHC}$ class I and class II molecules that present antigens to CD8 and CD4 T cells, respectively. Thus, B-cell lymphomas are unique among cancers in that tumor cells can express both MHC class I and class II as APCs (de Charette et al., 2016). To minimize the recognition by T cells and achieve immune evasion during lymphomagenesis, B-cell lymphomas commonly downregulate MHC class I and class II (Xu-Monette et al., 2018). For instance, more than $50 \%$ of diffuse large B-cell lymphoma (DLBCL) and $60 \%$ of

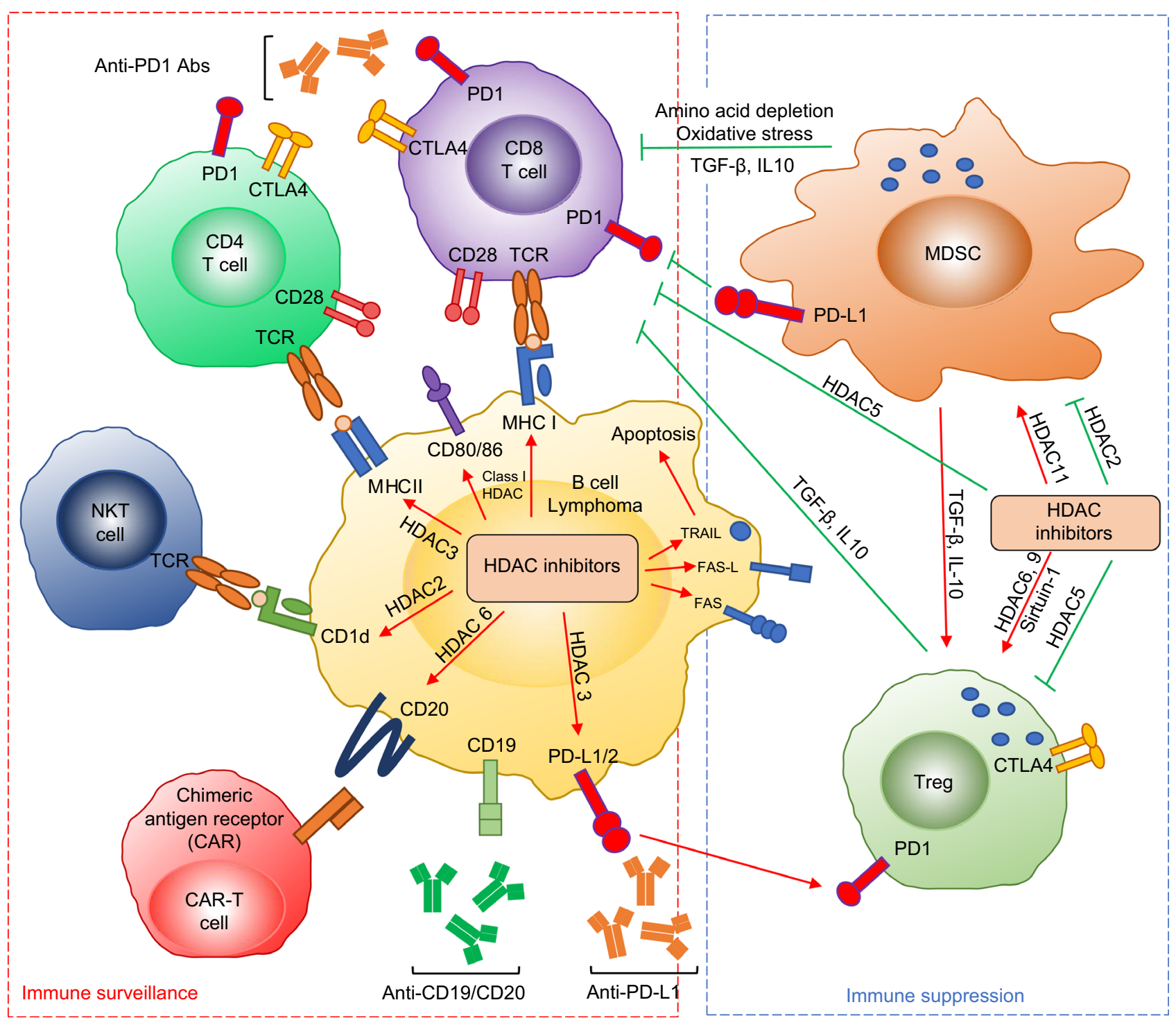

Figure 1. The interaction between HDAC inhibitors and immune system in B-cell lymphoma. Red arrow means increase or activation and green arrow means inhibition. 
classical Hodgkin lymphoma (HL) present the loss of $\mathrm{MHC}$ class I expression (Challa-Malladi et al., 2011; de Charette and Houot, 2018), and diminished MHC class II expression also frequently occurs not only in DLBCL but also in other types of mature B-cell lymphomas (Rimsza et al., 2004; Roberts et al., 2006; Diepstra et al., 2007a; Fangazio et al., 2014; de Charette et al., 2016; Nijland et al., 2017). We recently established a unique mouse model by lineagespecific deletion of a DNA repair gene, Xrcc4, and Trp53 in GC B cells (Chen et al., 2016). This mouse strain spontaneously develops mature B-cell lymphomas, termed G1XP lymphomas (Chen et al., 2016). G1XP lymphomas resemble the key features of human B-cell lymphomas including reciprocal chromosomal translocations and elevated expression of c-myc (Chen et al., 2016) and downregulation of MHC class I and class II expression (Wang et al., 2019). Downregulation or loss of $\mathrm{MHC}$ class I reduces tumor immunogenicity, decreases the percentage of CD8 and CD4 tumor infiltrating lymphocytes (TILs) and causes resistance to immunotherapy, which correlates to poor prognosis and patient survival (Garrido et al., 2016). Defects in MHC class II expression are associated with reduced $T$ cell infiltration (Rimsza et al., 2004) and inferior survival in patients of DLBCL, primary mediastinal B-cell lymphoma (PMBCL) or HL (Rimsza et al., 2004; Roberts et al., 2006; Diepstra et al., 2007b), as well as poor prognosis in patients of DLBCL and PMBCL following different chemotherapy regimens (Rosenwald et al., 2002; Rimsza et al., 2004; Roberts et al., 2006; Rimsza et al., 2007; Rimsza et al., 2008).

There are two types of MHC down-regulation: irreversible genetic alterations ('hard lesions') and reversible epigenetic changes ('soft lesions') (Garrido et al., 2010). Comparing with irreversible alterations, reversible downregulation of $\mathrm{MHC}$ is usually mediated by epigenetic modifications (Garrido et al., 2010). In human cancers, reversible downregulation dominates the defects in MHC class I expression (Smahel, 2017). Notably, reversible downregulation of $\mathrm{MHC}$ class II is mediated by decreased histone acetylation rather than DNA hyper-methylation in DLBCLs (Cycon et al., 2013). Since antigen presentation by tumor cells in the context of MHCs is generally regarded as a prerequisite for effective cancer immunotherapy (Nijland et al., 2017), downregulation of $\mathrm{MHC}$ expression represents a contributing factor in immunotherapy resistance (Sharma et al., 2017). Our recent studies show that B-cell lymphomas with low MHC expression resist PD-1 blockade; furthermore, upregulating $\mathrm{MHC}$ expression sensitizes B-cell lymphomas to PD-1 blockade (Wang et al., 2019). While HLs frequently reduce MHC class I expression, HLs exhibit a high response rate to PD-1 blockade (Roemer et al., 2016; Ok and Young, 2017), suggesting that the therapeutic effect of PD-1 blockade may not be only restricted to $\mathrm{MHC}$ class I-dependent CD8 T cellmediated killing. In this regard, HLs generally express more
MHC class II than MHC class I and are enriched for contact with CD4 T cells rather than CD8 T cells, which indicates that MHC class II may play a significant role in mediating responses to PD-1 blockade (Carey et al., 2017). Consistently, our data support that increased MHC class II contributes to the therapeutic effects of PD-1 blockade (Wang et al., 2019).

CD20 is expressed on the surface of B cells starting from late pro-B cells through memory B cells, but not on either early pro-B cells or plasma blasts and plasma cells (Murphy and Weaver, 2017). CD20 is also expressed on the surface of neoplastic B cells (Olejniczak et al., 2006). Several chimeric monoclonal anti-CD20 antibodies were developed to target CD20 for treating B-cell lymphomas (Maloney, 2012). However, multiple mechanisms may underlie resistance to anti-CD20 therapy. Firstly, CD20 expression varies considerably between different lymphoma subtypes or within a given subtype, which correlates with clinical responses to anti-CD20 (Olejniczak et al., 2006; Johnson et al., 2009). Secondly, a gradual loss of CD20 surface expression is detected in neoplastic $B$ cells with repeated exposure to antiCD20 antibody (Hiraga et al., 2009; Tsai et al., 2012). Thirdly, epigenetic mechanisms may also contribute to the downregulation of CD20 expression upon anti-CD20 treatment (Hiraga et al., 2009). Recently, CAR T cell immunotherapy against CD20 or CD19 has been developed to treat relapsed or refractory B-cell malignancies (Zhou et al., 2018). Despite the impressive remission rates of CAR T cell therapy, some patients develop initial resistance or relapse upon this novel therapy (Park et al., 2018). The resistant mechanisms of CAR T cell therapy have been extensively reviewed elsewhere (Cheng et al., 2019). For the CAR T cell-treated relapsed $B$-cell lymphoma patients, tumors can escape the recognition of CAR T cells by losing the very antigens targeted by CAR T cells (Shalabi et al., 2018; Shah et al., 2019). We summarize the current approved immunotherapeutic agents for treating B-cell lymphomas (Table 1), including monoclonal antibodies, antibody-drug conjugates (e.g., Brentuximab vedotin and polatuzumab vedotin-piiq (Polivy)) (Chau et al., 2019), immune checkpoint inhibitors and CAR T cells (Shah et al., 2019).

Myeloid-derived suppressor cells (MDSCs) have been shown to contribute to the immunosuppressive tumor microenvironment and tumor progression in B-cell lymphomas (Betsch et al., 2018). In particular, MDSCs may suppress T cell functions via expressing PD-L1, secreting IL10/TGF- $\beta$, inducing $T$ regulatory (Treg) development and expansion, and depleting certain amino acids (Serafini et al., 2008; Azzaoui et al., 2016; Roussel et al., 2017). Increased MDSCs are observed in various B-cell lymphomas, including $\mathrm{HL}$, DLBCL and follicular lymphoma (FL), which correlates with poor prognosis and overall survival of patients (Roussel et al., 2017; Betsch et al., 2018). Hence, MDSCs may also 
Table 1. Approved immunotherapeutic agents for B-cell lymphomas

\begin{tabular}{llll}
\hline Therapy type & Name & Target & Subtype \\
\hline Monoclonal antibodies & Rituximab & CD20 & NHL \\
& Obinutuzumab & CD20 & FL \\
& Brentuximab vedotin & CD30 & Relapsed or refractory HL \\
& Polatuzumab vedotin-piiq & CD79b & DLBCL \\
Immune checkpoint inhibitors & Nivolumab & PD1 & Relapsed or refractory HL \\
& Pembrolizumab & PD1 & Refractory HL and PMBCL \\
CAR T cells & Axicabtagene ciloleucel & CD19 & DLBCL, transformed FL, PMBCL 2019 \\
& Tisagenlecleucel & CD19 & Relapsed or refractory LBCL 2017 \\
\hline
\end{tabular}

DLBCL: diffuse large B-cell lymphoma; FL: follicular lymphoma; HL: Hodgkin lymphoma; LBCL: large B-cell lymphoma; NHL: non-Hodgkin lymphoma; PMBCL: primary mediastinal B-cell lymphoma.

play a role in causing resistance to cancer immunotherapy in B-cell lymphomas.

\section{HDAC AND HDAC INHIBITORS IN B-CELL LYMPHOMAS}

Histone acetylation level is determined by a dynamic equilibrium between histone acetyl transferases (HATs) and histone deacetylases (HDACs); namely, HATs add acetyl groups to histone lysine residues while HDACs remove them. HDACs consist of a large family of proteins categorized into five groups, class I (HDAC 1, 2, 3, 8), class Ila (HDAC 4, 5, 7, 9), class IIb (HDAC 6, 10), class III (Sirtuins) and class IV (HDAC 11). Dysregulation of histone acetylation can lead to aberrant gene expression, which can activate oncogenes, inactivate tumor suppressors, inhibit programed cell death and mediate immune evasion, ultimately resulting in tumor progression (Kroesen et al., 2014). Aberrant HDAC expression occurs in both solid tumors and hematological cancers, including B-cell lymphomas (Ropero and Esteller, 2007; Zain and O'Connor, 2010; Lee et al., 2014). Prior findings show that dysregulation of histone acetylation contributes to lymphomagenesis, particularly in GC-derived lymphomas (Sermer et al., 2019). Constitutive expression of HDAC 9 throughout B cell development in mice causes splenic marginal zone lymphoma and lymphoproliferative disease that progresses towards aggressive DLBCL (Gil et al., 2016). Taken together, HDACs may serve as potential targets of chemical intervention for treating B-cell lymphomas (Table 2).

To date, four HDAC inhibitors, vorinostat, romidepsin, panobinostat, and belinostat, have been approved by the United States Food and Drug Administration and are used for hematologic cancers in clinic (Yoon and Eom, 2016). In addition, several new HDAC inhibitors have been tested in clinical trials against different types of tumors, however, single treatment regimens have poor therapeutic effect on solid tumors (Thurn et al., 2011). Despite the success of
FDA-approved HDACi, each has intrinsic liabilities including poor isoform selectivity, marginal potencies towards relevant isoforms, narrow therapeutic indices and/or non-oral delivery routes. These drawbacks have spurred a continuous search for alternatives with improved biological, physiochemical and therapeutic properties. Luesch and colleagues reported a natural product, largazole, as a potent class I HDACi (Taori et al., 2008; Ying et al., 2008); however, largazole has relatively poor physiochemical properties and is not amenable to large-scale chemical manufacturing. Thus, a lead optimization program was initiated that resulted in the discovery of next generation largazole derivatives OKI-005 and OKI179 (Liu et al., 2013). Our recent studies show that combined treatment of OKI-179/anti-PD1 significantly inhibited growth of B-cell lymphomas refractory to PD1-blockade; furthermore, sensitivity to single or combined treatment required tumor-derived $\mathrm{MHC}$ class I, and positively correlated to $\mathrm{MHC}$ class II level (Wang et al., 2019). Here, we focus on the rationale and therapeutic promise of combining HDAC inhibitors with immunotherapy in the treatment of B-cell lymphoma.

\section{CYTOTOXICITY OF HDAC INHIBITORS}

HDAC inhibitors can suppress tumor growth via multiple mechanisms (Table 2). Mocetinostat, a class I/IV HDAC inhibitor, induces cell apoptosis and cell cycle arrest, and downregulates Bcl-2 in HL cell lines (Huang et al., 2018). A pan-HDAC inhibitor, panobinostat, can induce cell death, autophagy, and an increase of MICA/B, ligands of NK cell receptors in $\mathrm{HL}$ cell lines (Klein et al., 2013). Entinostat, a class I HDAC inhibitor, decreases Bcl-XL levels and induces caspase-dependent/independent apoptosis in B-cell lymphomas (Frys et al., 2015), while entinostat induces caspase-dependent apoptosis in B-cell chronic lymphocytic leukemia cells (Lucas et al., 2004). In addition, the anti-tumorigenic effects of HDAC inhibitors can be mediated by the activation of TRAIL and Fas signaling pathways in leukemia 
Table 2. The application of HDAC inhibitors to B-cell lymphoma (BCL)

\begin{tabular}{|c|c|c|c|}
\hline Names & Potential mechanisms of action & $\begin{array}{l}\text { Target } \\
\text { (HDAC) }\end{array}$ & Subtype \\
\hline Apicidin & Upregulate $\mathrm{MHC}$ I and II & $\mathrm{HDAC} 3 / 6$ & DLBCL \\
\hline Belinostat & Induce cell death, upregulate $\mathrm{MHC}$ I and II & $\begin{array}{l}\mathrm{HDAC} 1 / 2 / 3 / \\
4 / 5 / 6 / 7 / 8 / \\
9 / 10 / 11\end{array}$ & $\begin{array}{l}\text { DLBCL, MCL, FL, TL, HG- } \\
\text { BCL, BL, PMBCL }\end{array}$ \\
\hline Citarinostat & Induce cell death & HDAC6 & $\mathrm{FL}, \mathrm{MCL}, \mathrm{HL}$ \\
\hline $\mathrm{Cl}-994$ & Induce cell death & HDAC $1 / 3$ & PEL, canine BCL \\
\hline Entinostat & Induce cell death, upregulate $\mathrm{MHC}$ I and II, CD20, reduce MDSC & $\begin{array}{l}\operatorname{HDAC} 1 / 2 / 3 / \\
10\end{array}$ & HL, NHL, DLBCL, BL \\
\hline MC1568 & CD1d-mediated antigen presentation & $\begin{array}{l}\text { HDAC } 4 / 5 / 6 / \\
7 / 9 / 10\end{array}$ & MCL \\
\hline Mocetinostat & Induce cell death, upregulate PD-L1 & $\begin{array}{l}\text { HDAC } 1 / 2 / 3 / \\
11\end{array}$ & $\mathrm{HL}, \mathrm{DLBCL}, \mathrm{FL}$ \\
\hline MPT0E028 & Induce cell death & HDAC1/2/6 & $\mathrm{BL}$ \\
\hline $\begin{array}{l}\text { OKI-5/OKI- } \\
179\end{array}$ & Induce cell death, upregulate PD-L1, MHC I and II & $\begin{array}{l}\mathrm{HDAC} 1 / 2 / 3 / \\
6 / 8 / 10 / 11\end{array}$ & DLBCL, murine $B C L$ \\
\hline Panobinostat & $\begin{array}{l}\text { Induce cell death, CD1d-mediated antigen presentation, upregulate } \\
\text { PD-L1, inhibit CD4/8 T cells }\end{array}$ & $\begin{array}{l}\mathrm{HDAC} 1 / 2 / 3 / \\
4 / 5 / 6 / 7 / 8 / \\
9 / 10 / 11\end{array}$ & $\begin{array}{l}\mathrm{HL} \text {, DLBCL, MCL, BL, } \\
\text { murine and canine BCL }\end{array}$ \\
\hline RGFP966 & Induce cell death, upregulate MHC I, CD80, CD86, PD-L1 & HDAC3 & DLBCL, murine BCL \\
\hline Ricolinostat & Induce cell death & HDAC6 & DLBCL, MCL, FL \\
\hline Romidepsin & $\begin{array}{l}\text { Induce cell death, upregulate MHC I, CD80, CD86, CD20, NKG2D } \\
\text { ligands }\end{array}$ & HDAC $1 / 2$ & $\begin{array}{l}\text { BL, DLBCL, MCL, murine } \\
\text { BCL }\end{array}$ \\
\hline SBHA & Induce cell death & HDAC1/3 & MCL, PEL, canine BCL \\
\hline Scriptaid & Induce cell death & $\mathrm{HDAC} 1 / 3 / 8$ & DLBCL, canine BCL \\
\hline $\begin{array}{l}\text { Sodium } \\
\text { butyrate }\end{array}$ & Induce cell death, upregulate $\mathrm{MHC}$ I and II & $\mathrm{HDAC} 1 / 2 / 3$ & BL, FL, PEL, DLBCL \\
\hline $\begin{array}{l}\text { Trichostatin } \\
\text { A }\end{array}$ & $\begin{array}{l}\text { Induce cell death, upregulate } \mathrm{MHC} \text { I and II, MHC II-mediated antigen } \\
\text { presentation, CD1d-mediated antigen presentation, upregulate } \\
\text { PD-L1, activate Tregs }\end{array}$ & $\begin{array}{l}\mathrm{HDAC} 1 / 2 / 3 / \\
6 / 8 / 10 / 11\end{array}$ & $\begin{array}{l}\text { DLBCL, MCL, murine and } \\
\text { canine } B C L\end{array}$ \\
\hline Tubacin & Induce cell death, activate Tregs & HDAC6 & $\mathrm{BL}$, canine $\mathrm{BCL}$ \\
\hline Tubastatin A & Induce cell death, activate Tregs & HDAC6 & DLBCL, MCL \\
\hline Valproic acid & $\begin{array}{l}\text { Induce cell death, upregulate MHC I and II, CD80, CD86, PD-L1, } \\
\text { CD20, activate Tregs }\end{array}$ & HDAC $1 / 2$ & $\begin{array}{l}\mathrm{BL}, \mathrm{DLBCL}, \mathrm{MCL} \text {, murine } \\
\text { BCL }\end{array}$ \\
\hline Vorinostat & Induce cell death, upregulate PD-L1, activate Tregs & $\begin{array}{l}\text { HDAC } 1 / 2 / 3 / \\
5 / 6 / 8 / 9 / 10 / \\
11\end{array}$ & $\begin{array}{l}\text { FL, DLBCL, HL, MCL, } \\
\text { iNHL, BL, murine and } \\
\text { canine BCL }\end{array}$ \\
\hline
\end{tabular}

BL: Burkitt lymphoma; DLBCL: diffuse large B-cell lymphoma; FL: follicular lymphoma; HG-BCL: high grade B-cell lymphoma; HL: Hodgkin lymphoma; iNHL: indolent NHL; MCL: mantle cell lymphoma; NHL: non-Hodgkin lymphoma; PEL: primary effusion lymphoma; PMBCL: primary mediastinal B-cell lymphoma; TL: transformed lymphoma.

(Insinga et al., 2005). Seven HDAC inhibitors, including Cl994, panobinostat, SBHA, vorinostat, scriptaid, trichostatin A and tubacin, exhibit dose-dependent inhibitory effects on proliferation of a canine B-cell lymphoma line (Dias et al., 2018). Another pan-HDAC inhibitor, MPTOE028, shows a potent HDAC inhibitory effect, that leads to increased apoptosis, and prolongs the overall survival of recipient mice bearing human B-cell lymphoma in a xenograft model (Huang et al., 2015).

Our studies also demonstrate cytotoxic effects of HDAC inhibitors on B-cell lymphomas (Wang et al., 2019). Both OKI-005 and OKI-179 (class I, IIb, IV HDAC inhibitors) cause cell cycle arrest, apoptosis and growth inhibition in multiple murine and human B-cell lymphoma lines (Wang et al., 2019). Although OKI-179 displays direct cytotoxic effects on 
lymphomas, our studies highlight its immunological effects because we find that tumor-derived MHC class I is absolutely required for the therapeutic effects of OKI-179 single agent treatment (Wang et al., 2019). Thus, our data demonstrate that the therapeutic effects of OKI-179 mainly depend on its ability to modulate immune responses, instead of its anti-proliferative or pro-apoptotic role (Wang et al., 2019).

\section{IMMUNE MODULATION OF B-CELL LYMPHOMAS BY HDAC INHIBITORS}

Since $\mathrm{MHC}$ class I expression is often reduced by epigenetic mechanisms in cancers, HDAC inhibitors can upregulate $\mathrm{MHC}$ class I in various types of cancers (Grunewald et al., 2018). In DLBCL cell lines, HDAC inhibitors (trichostatin A, sodium butyrate, apicidin and entinostat) induce MHC class I expression (Cycon et al., 2013). Valproic acid (class I HDAC inhibitor), romidepsin (HDAC1/2 inhibitor) or RGFP966 (HDAC3 inhibitor) upregulates MHC class I expression and costimulatory molecules, such as CD80 and CD86, in B-cell lymphomas (Deng et al., 2019). Histone deacetylation typically induces a closed chromatin state at the MHC class II promoters, resulting in downregulation of $\mathrm{MHC}$ class II in tumors. HDAC inhibitors, including trichostatin $A$, sodium butyrate, apicidin, valproic acid and entinostat, increase MHC class II expression in DLBCL (Cycon et al., 2013). In mantle cell lymphoma (MCL), trichostatin $A$ treatment enhances $\mathrm{MHC}$ class II-mediated antigen presentation, even though MHC class II expression remains unaltered (Tiper and Webb, 2016). Crebbp deficiency was shown to promote B-cell lymphomagenesis with a HDAC3-mediated enhancer repression signature, including the downregulation of $\mathrm{MHC}$ class II (Jiang et al., 2017). Inhibiting HDAC3 restored the expression of MHC class II in Crebbp-deficient cells, thus enhancing T cell proliferation (Jiang et al., 2017). Our studies also show $\mathrm{OKI}$ significantly enhance $\mathrm{MHC}$ class I and class II expression in G1XP lymphoma both in vitro and in vivo (Wang et al., 2019). However, OKI-179 upregulated HLA-DP, DQ and DR in OCl-Ly3 cells, but not in OCl-Ly1, OCl-Ly7 and SU-DHL-16 cells (Wang et al., 2019). Thus, different human B-cell lymphoma lines respond differentially to OKI179 treatment in terms of MHC upregulation (Wang et al., 2019).

HDAC inhibitors affect not only classical MHC expression but also non-classical MHC expression such as CD1d. CD1d mediates antigen presentation to NKT cells, a subset of $\mathrm{T}$ cells that recognize lipid antigens. In $\mathrm{MCL}$, treatments with trichostatin A, panobinostat or MC1568 rapidly enhances CD1d-mediated antigen presentation (Tiper and Webb, 2016). Mechanistically, HDAC2 can bind to the promoter of CD1d and HDAC2 knockdown in tumor cells results in a significant increase of CD1d surface expression, thus enhancing CD1d-mediated immune recognition and activation of NKT cells (Tiper and Webb, 2016). Trichostatin A can also enhance CD1d antigen presentation via abrogating the secretion of IL-10 by tumor cells (Tiper and Webb, 2016). $\alpha$ GalCer is a glycolipid antigen presented by CD1d and a potent activator of iNKT cells. In a preclinical B-cell lymphoma murine model, the combination of $\alpha-G a l C e r$ and vorinostat significantly reduced tumor burden and increased recipient survival compared to single agent treatment (West et al., 2013).

PD-L1 expression in cancer cells has been associated with intrinsic aggressive features, which provides a rationale for developing new drugs to target PD-L1 expression directly or to potentiate therapeutic effects by combining drugs with PD-1/PD-L1 inhibitors. In this regard, multiple HDAC inhibitors can modulate PD-L1 expression. Class I HDAC inhibitors (entinostat, mocetinostat, panobinostat and belinostat) have been shown to generate robust and durable upregulation of PD-L1 and PD-L2 in tumor cells; however, this upregulation was not observed upon inhibiting Class Ila HDACs or HDAC 6 with rocilinostat, nexturastat A or PCl34051 (Woods et al., 2015). Mocetinostat increases PDL1 expression in multiple HL cell lines (Huang et al., 2018). Pan-HDAC inhibitors, such as vorinostat, TSA and panobinostat, induce PD-L1 expression in B-cell lymphomas (Deng et al., 2019). Selective HDAC3 inhibitors (e.g., RGFP966) also upregulated PD-L1 expression because HDAC3 was shown to repress PD-L1 transcription in B-cell lymphomas (Deng et al., 2019). We showed that OKI-179 also upregulated PD-L1 expression in B-cell lymphomas but not in primary B cells (Wang et al., 2019). Notably, OKI-179 exhibits potent inhibitory activities on HDAC 1, 2 and 3 (Wang et al., 2019), consistent with the notion that HDAC3 is a crucial repressor of PD-L1 transcription (Deng et al., 2019).

Prior studies show that tumor-derived PD-L1 is not required for the efficacy of anti-PD-L1 treatment because host myeloid cells still express PD-L1 that is essential for the response to anti-PD-L1 (Tang et al., 2018). It remains to be determined whether altering tumor-derived PD-L1 will affect the efficacy of combined treatment of OKI-179/anti-PD1 in our B-cell lymphoma model (Wang et al., 2019). Based on these prior studies, we suggest that HDACi-mediated PD-L1 upregulation may explain why these agents generally fail to treat cancers as a single agent. Our studies may provide novel insights into why HDACi alone failed and why there should be a renewed emphasis on the combined therapies of HDACi and ICls.

Downregulation of CD20 is a clinical issue that leads to decreased efficacy of anti-CD20-based therapeutic regimens. Entinostat increases the expression of CD20 and adhesion molecules in multiple B-cell lymphomas, thereby sensitizing B-cell lymphomas to the treatment of anti-CD20 monoclonal antibodies (Frys et al., 2015). Furthermore, inhibiting HDAC 6 significantly upregulates CD20 expression in $B$ cell tumors and enhances the efficacy of anti-CD20 monoclonal antibodies (Bobrowicz et al., 2017). HDAC inhibitors, valproic acid and romidepsin, can transactivate the CD20 gene via promoter hyperacetylation and Sp1 
recruitment (Shimizu et al., 2010); therefore, both HDAC inhibitors increase CD20 expression in B-cell lymphoma lines and reduce the growth of B-cell lymphomas synergistically with anti-CD20 monoclonal antibodies. Phase II trials were performed to combine HDAC inhibitors (panobinostat or vorinostat) and rituximab (an anti-CD20 antibody) in patients with DLBCL or indolent NHL (Chen et al., 2015; Assouline et al., 2016). CD20 CAR T cells are being tested in clinical trial for NHL; however, tumor cells can lose or downregulate CD20 expression (Shah et al., 2019). We suggest that combining HDAC inhibitors with CAR T cells may provide another novel approach to overcome resistance to CAR T cell therapy.

Apart from alterations in antigen expression, cancer cells may acquire resistance to CAR T cell therapy by dysregulating their apoptotic machinery, such as apoptotic pathway mediated by tumor necrosis factor-related apoptosis-inducing ligand (TRAIL) (Torres-Collad and Jazirehi, 2018). When human NHL cell lines became resistant to CD19 CAR T cells, adding HDAC inhibitors, vorinostat (a.k.a. SAHA) or panobinostat, largely reversed their resistance to CD19 CAR $T$ cells (Torres-Collad and Jazirehi, 2018). Studies also indicate that vorinostat sensitized CD19 CAR T cell-resistant Ramos cells to TRAIL-mediated killing (Torres-Collad and Jazirehi, 2018), although the detailed mechanisms remain to be defined. HDAC inhibitors including vorinostat have been shown to upregulate the expression of death receptor 5 (DR5), a receptor for TRAIL, on human cancer cells (Nakata et al., 2004). Thus, we suggest that HDAC inhibitors may function by modulating death receptor expression (e.g., DR5) in cancer cells and enhance their sensitivity to players in extrinsic apoptotic pathways (e.g., TRAIL). In addition, HDAC inhibitors have been reported to improve the function of CAR NK cells (Chu et al., 2015; Chu et al., 2017). Romidepsin significantly enhances the expression of NKG2D ligands in cancer cells that can activate NKG2D expressed in NK cells, thereby enhancing the cytotoxicity of anti-CD20 CAR NK cells to romidepsin-treated Burkitt lymphoma cells (Chu et al., 2015; Chu et al., 2017). In humanized Raji xenograft NSG mice, combined treatment with romidepsin and anti-CD20 CAR NK cells achieves a better therapeutic efficacy than single agent treatment (Chu et al., 2015; Chu et al., 2017).

\section{EFFECTS OF HDAC INHIBITORS ON IMMUNE CELLS}

HDAC inhibitors not only affect cancer cells but also modulate immune cell functions. Some HDAC inhibitors have direct effects on T cells. Trichostatin A causes a rapid decline in cytokine expression, arrests cell cycle at G1 phase and induces apoptosis of CD4 T cells (Moreira et al., 2003). However, another study shows that trichostatin A can inhibit apoptosis of tumor infiltrating CD4 T cells by suppressing NFAT1-regulated Fas ligand expression on activated CD4 T cells and thereby enhance anti-tumor immune responses (Cao et al., 2015). Tregs are responsible for inhibiting or regulating immune responses by suppressing effector $T$ cells. Previous studies show that exposure to multiple HDAC inhibitors enhances the suppressive function of Tregs, correlative to increased FOXP3 and CTLA-4 expressions in Tregs (Tao et al., 2007; Akimova et al., 2010). Further data show that inhibiting HDAC6, HDAC9 or the class III HDAC Sirtuin-1 promotes the suppressive activity of Tregs (Tao et al., 2007; Beier et al., 2011; de Zoeten et al., 2011). The knockout of HDAC5 reduces the differentiation and suppressive function of Tregs (Xiao et al., 2016). However, CD8 T cells without HDAC5 have a reduced ability to produce IFN-y (Xiao et al., 2016). Our study shows that OKI, along with vorinostat, has no effect on the proliferation and activation of CD4 and CD8 T cells (Wang et al., 2019). In contrast, panobinostat significantly inhibits the proliferation and activation of CD4 and CD8 T cells at a low concentration (Wang et al., 2019), suggesting that such low therapeutic windows probably make it unsuitable for combinations with ICls. Due to the cytotoxicity of HDAC inhibitors and their variable effects on Tregs, it is critical to consider their direct effects on $\mathrm{T}$ cells in the application of HDAC inhibitors for cancer immunotherapy.

MDSCs are a myeloid population, capable of suppressing various T-cell functions in the tumor microenvironment. In HDAC11-defcient mice, MDSCs are highly suppressive and transplanted $\mathrm{T}$ cell lymphomas are more aggressive compared to wild-type controls (Sahakian et al., 2015). Adding entinostat to PD-1 and CTLA-4 blockade significantly reduces the number of MDSCs, leading to enhanced tumor control and reduced metastasis (Kim et al., 2014); however, it remains unknown which HDACs mediate such effects. Based on its biochemical profile, entinostat inhibits the activity of HDAC 1, 2, and 3 but not HDAC 11 (Wang et al., 2019). Hence, it may be also important to consider the effects of HDAC inhibitors on MDSCs when using them for cancer immunotherapy.

\section{PERSPECTIVES AND FUTURE DIRECTIONS}

Lack of selectivity of many HDAC inhibitors may contribute to toxicities against healthy cells in clinical applications and trials. Nonselective HDAC inhibitors target multiple HDACs, which usually cause serious adverse events, including thrombocytopenia, fatigue and diarrhea (Gryder et al., 2012). In addition, not all HDACi are created equal and their net effects are highly dependent on the specific inhibitors used and the HDACs they target (Kroesen et al., 2014; McCaw et al., 2017). Class I HDAC inhibitors have been shown to enhance the function of NK and CD8 T cells, reduce the number and function of Tregs, and in turn, result in antitumor immune responses in multiple tumor models (Kroesen et al., 2014). However, class II HDAC inhibitors directly enhance the immunosuppressive function of Tregs (Kroesen et al., 2014). Furthermore, inhibiting HDAC2 (class I HDAC) 
enables highly immunosuppressive tumor-induced MDSCs differentiate into macrophages and dendritic cells, which stimulates the immune system to target tumor cells (Youn et al., 2013). In contrast, pan-HDAC inhibition results in the accumulation of a pool of undifferentiated myeloid cells, which limits anti-tumor immune responses (Rosborough et al., 2012). Moreover, a pan-HDAC inhibitor, panobinostat, is very toxic to T cells, although it can also induce MHC expression (Wang et al., 2019). Since an intact immune system is required for the anti-B-cell lymphoma activities of HDAC inhibitors (West et al., 2013), it is important to consider isoform selectivity for the rational design of combinatorial immunotherapy using HDAC inhibitors; for instance, class I HDAC inhibitors may be more appropriate to be combined with ICls than class II or pan-HDAC inhibitors. Taken together, it is thereby ideal to seek HDAC isoformspecific inhibitors, which exhibit optimal biochemical features that allow their targeted use to enhance apoptosis of tumor cells, increase tumor immunogenicity, and reverse immunosuppressive tumor environments, thereby favoring anti-tumor immune responses.

\section{ACKNOWLEDGEMENTS}

This work was supported by University of Colorado School of Medicine and Cancer Center startup funds to J.H.W., Cancer League of Colorado, R21-CA184707, R21-Al110777, R01-CA166325, R21-Al133110 and R01-CA229174 to J.H.W., and a fund from American Cancer Society (ACS IRG \#16-184-56) to Z.C. X.G.W. was supported by an AAI Careers in Immunology Fellowship. R.A.W. is supported by a NIH F31 fellowship (F31DE027854). S.M.Y.C. is supported by a NIH T32 fellowship (T32 Al007405).

\section{AUTHORS' CONTRIBUTIONS}

All of the authors participated in the discussion and development of manuscript outlines, contributed to editing of the draft manuscript.

\section{ABBREVIATIONS}

AID, activation-induced deaminase; APCs, antigen-presenting cells; $\mathrm{CAR}$, chimeric antigen receptor; CSR, class switch recombination; DLBCL, diffuse large B-cell lymphoma; FL, follicular lymphoma; GC, germinal center; HATs, histone acetyl transferases; HDAC, histone deacetylase; HL, Hodgkin lymphoma; ICls, immune checkpoint inhibitors; Ig, immunoglobulin; MCL, mantle cell lymphoma; MDSCs, myeloid-derived suppressor cells; $\mathrm{MHC}$, major histocompatibility complex; NHL, non-Hodgkin lymphoma; PMBCL, primary mediastinal B-cell lymphoma; SHM, somatic hypermutation; TILs, tumor infiltrating lymphocytes; Treg, T regulatory

\section{COMPLIANCE WITH ETHICS GUIDELINES}

Xiaoguang Wang, Brittany C. Waschke, Rachel A Woolaver, Samantha M.Y. Chen, Zhangguo Chen and Jing H. Wang declare that they have no conflict of interest. Written informed consent for publication was obtained from all participants. This article does not contain any studies with human or animal subjects performed by any of the authors.

\section{OPEN ACCESS}

This article is licensed under a Creative Commons Attribution 4.0 International License, which permits use, sharing, adaptation, distribution and reproduction in any medium or format, as long as you give appropriate credit to the original author(s) and the source, provide a link to the Creative Commons licence, and indicate if changes were made. The images or other third party material in this article are included in the article's Creative Commons licence, unless indicated otherwise in a credit line to the material. If material is not included in the article's Creative Commons licence and your intended use is not permitted by statutory regulation or exceeds the permitted use, you will need to obtain permission directly from the copyright holder. To view a copy of this licence, visit http:// creativecommons.org/licenses/by/4.0/.

\section{REFERENCES}

Akimova T, Ge G, Golovina T, Mikheeva T, Wang L, Riley JL, Hancock WW (2010) Histone/protein deacetylase inhibitors increase suppressive functions of human FOXP3+ Tregs. Clin Immunol 136:348-363

Assouline SE, Nielsen TH, Yu S, Alcaide M, Chong L, MacDonald D, Tosikyan A, Kukreti V, Kezouh A, Petrogiannis-Haliotis T et al (2016) Phase 2 study of panobinostat with or without rituximab in relapsed diffuse large B-cell lymphoma. Blood 128:185-194

Azzaoui I, Uhel F, Rossille D, Pangault C, Dulong J, Le Priol J, Lamy T, Houot R, Le Gouill S, Cartron G et al (2016) T-cell defect in diffuse large B-cell lymphomas involves expansion of myeloidderived suppressor cells. Blood 128:1081-1092

Beier UH, Wang L, Bhatti TR, Liu Y, Han R, Ge G, Hancock WW (2011) Sirtuin-1 targeting promotes Foxp3+ T-regulatory cell function and prolongs allograft survival. Mol Cell Biol 31:10221029

Betsch A, Rutgeerts O, Fevery S, Sprangers B, Verhoef G, Dierickx D, Beckers M (2018) Myeloid-derived suppressor cells in lymphoma: the good, the bad and the ugly. Blood Rev 32:490498

Bobrowicz M, Dwojak M, Pyrzynska B, Stachura J, Muchowicz A, Berthel E, Dalla-Venezia N, Kozikowski M, Siernicka M, Miazek N et al (2017) HDAC6 inhibition upregulates CD20 levels and increases the efficacy of anti-CD20 monoclonal antibodies. Blood 130:1628-1638

Bray F, Ferlay J, Soerjomataram I, Siegel RL, Torre LA, Jemal A (2018) Global cancer statistics 2018: GLOBOCAN estimates of incidence and mortality worldwide for 36 cancers in 185 countries. CA-A Cancer Journal for Clinicians 68:394-424

Cao K, Wang G, Li W, Zhang L, Wang R, Huang Y, Du L, Jiang J, Wu $\mathrm{C}, \mathrm{He} \mathrm{X}$ et al (2015) Histone deacetylase inhibitors prevent activation-induced cell death and promote anti-tumor immunity. Oncogene 34:5960-5970 
Carey CD, Gusenleitner D, Lipschitz M, Roemer MGM, Stack EC, Gjini E, Hu X, Redd R, Freeman GJ, Neuberg D et al (2017) Topological analysis reveals a PD-L1-associated microenvironmental niche for Reed-Sternberg cells in Hodgkin lymphoma. Blood 130:2420-2430

Challa-Malladi M, Lieu YK, Califano O, Holmes AB, Bhagat G, Murty VV, Dominguez-Sola D, Pasqualucci L, Dalla-Favera R (2011) Combined genetic inactivation of beta 2-Microglobulin and CD58 reveals frequent escape from immune recognition in diffuse large B cell lymphoma. Cancer Cell 20:728-740

Chau CH, Steeg PS, Figg WD (2019) Antibody-drug conjugates for cancer. Lancet 394:793-804

Chen R, Frankel P, Popplewell L, Siddiqi T, Ruel N, Rotter A, Thomas SH, Mott M, Nathwani N, Htut M et al (2015) A phase II study of vorinostat and rituximab for treatment of newly diagnosed and relapsed/refractory indolent non-Hodgkin lymphoma. Haematologica 100:357-362

Chen Z, Elos MT, Viboolsittiseri SS, Gowan K, Leach SM, Rice M, Eder MD, Jones K, Wang JH (2016) Combined deletion of Xrcc4 and Trp53 in mouse germinal center B cells leads to novel B cell lymphomas with clonal heterogeneity. J Hematol Oncol 9:2

Chen Z, Wang JH (2014) Generation and repair of AID-initiated DNA lesions in B lymphocytes. Front Med 8:201-216

Cheng J, Zhao L, Zhang Y, Qin Y, Guan Y, Zhang T, Liu C, Zhou J (2019) Understanding the mechanisms of resistance to CAR T-cell therapy in malignancies. Front Oncol 9:1237

Chu Y, Yahr A, Ayello J, Cairo MS (2015) Effectively targeting Burkitt lymphoma by anti-CD20 chimeric antigen receptor (CAR) modified expanded natural killer cells combined with a histone deacetylase inhibitor, romidepsin in vitro and in humanized NSG mice. Biol Blood Marrow Transplant 21:S152-S153

Chu Y, Yahr A, Huang B, Ayello J, Barth MS, Cairo M (2017) Romidepsin alone or in combination with anti-CD20 chimeric antigen receptor expanded natural killer cells targeting Burkitt lymphoma in vitro and in immunodeficient mice. Oncoimmunology 6:e1341031

Cycon KA, Mulvaney K, Rimsza LM, Persky D, Murphy SP (2013) Histone deacetylase inhibitors activate CIITA and MHC class II antigen expression in diffuse large B-cell lymphoma. Immunology 140:259-272

de Charette M, Houot R (2018) Hide or defend, the two strategies of lymphoma immune evasion: potential implications for immunotherapy. Haematologica 103:1256-1268

de Charette M, Marabelle A, Houot R (2016) Turning tumour cells into antigen presenting cells: The next step to improve cancer immunotherapy? Eur J Cancer 68:134-147

de Zoeten EF, Wang L, Butler K, Beier UH, Akimova T, Sai H, Bradner JE, Mazitschek R, Kozikowski AP, Matthias $P$ et al (2011) Histone deacetylase 6 and heat shock protein 90 control the functions of Foxp3(+) T-regulatory cells. Mol Cell Biol 31:2066-2078

Deng S, Hu Q, Zhang H, Yang F, Peng C, Huang C (2019) HDAC3 inhibition upregulates PD-L1 expression in B-cell lymphomas and augments the efficacy of anti-PD-L1 therapy. Mol Cancer Ther 18:900-908

Dias JN, Aguiar SI, Pereira DM, André AS, Gano L, Correia JD, Carrapiço B, Rütgen B, Malhó R, Peleteiro C (2018) The histone deacetylase inhibitor panobinostat is a potent antitumor agent in canine diffuse large B-cell lymphoma. Oncotarget 9:28586

Diepstra A, Van Imhoff GW, Karim-Kos HE, Van den Berg A, Meerman GJT, Niens M, Nolte IM, Bastiaannet E, Schaapveld M, Vellenga $E$ et al (2007a) HLA class II expression by Hodgkin Reed-Sternberg cells is an independent prognostic factor in classical Hodgkin lymphoma. Haematologica 92:40-41

Diepstra A, van Imhoff GW, Karim-Kos HE, van den Berg A, te Meerman GJ, Niens M, Nolte IM, Bastiaannet E, Schaapveld M, Vellenga $\mathrm{E}$ et al (2007b) HLA class II expression by Hodgkin Reed-Sternberg cells is an independent prognostic factor in classical Hodgkin's lymphoma. J Clin Oncol 25:3101-3108

Fangazio M, Dominguez-Sola D, Tabbo F, Rossi D, Teruya-Feldstein J, Boldorini R, Gaidano G, Bhagat G, Inghirami G, Pasqualucci L et al (2014) Genetic mechanisms of immune escape in diffuse large B cell lymphoma. Blood 124:1692

Frys S, Simons Z, Hu Q, Barth MJ, Gu JJ, Mavis C, Skitzki J, Song L, Czuczman MS, Hernandez-Ilizaliturri FJ (2015) Entinostat, a novel histone deacetylase inhibitor is active in B-cell lymphoma and enhances the anti-tumour activity of rituximab and chemotherapy agents. Br J Haematol 169:506-519

Garrido F, Aptsiauri N, Doorduijn EM, Lora AMG, van Hall T (2016) The urgent need to recover MHC class I in cancers for effective immunotherapy. Curr Opin Immunol 39:44-51

Garrido F, Cabrera T, Aptsiauri N (2010) "Hard" and "soft" lesions underlying the HLA Class I alterations in cancer cells: implications for immunotherapy. Int J Cancer 127:249-256

Gil VS, Bhagat G, Howell L, Zhang J, Kim CH, Stengel S, Vega F, Zelent A, Petrie K (2016) Deregulated expression of HDAC9 in B cells promotes development of lymphoproliferative disease and lymphoma in mice. Dis Model Mech 9:1483-1495

Grunewald CM, Schulz WA, Skowron MA, Hoffmann MJ, Niegisch G (2018) Tumor immunotherapy-the potential of epigenetic drugs to overcome resistance. Transl Cancer Res 7:1151-1160

Gryder BE, Sodji QH, Oyelere AK (2012) Targeted cancer therapy: giving histone deacetylase inhibitors all they need to succeed. Future Med Chem 4:505-524

Hiraga J, Tomita A, Sugimoto T, Shimada K, Ito M, Nakamura S, Kiyoi H, Kinoshita T, Naoe T (2009) Down-regulation of CD20 expression in B-cell lymphoma cells after treatment with rituximab-containing combination chemotherapies: its prevalence and clinical significance. Blood 113:4885-4893

Huang HL, Peng CY, Lai MJ, Chen CH, Lee HY, Wang JC, Liou JP, Pan SL, Teng CM (2015) Novel oral histone deacetylase inhibitor, MPTOE028, displays potent growth-inhibitory activity against human B-cell lymphoma in vitro and in vivo. Oncotarget 6:4976-4991

Huang RH, Zhang XW, Min ZJ, Shadia AS, Yang SE, Liu XJ (2018) MGCD0103 induces apoptosis and simultaneously increases the expression of NF-kappa B and PD-L1 in classical Hodgkin's lymphoma. Exp Ther Med 16:3827-3834

Insinga A, Monestiroli S, Ronzoni S, Gelmetti V, Marchesi F, Viale A, Altucci L, Nervi C, Minucci S, Pelicci PG (2005) Inhibitors of histone deacetylases induce tumor-selective apoptosis through activation of the death receptor pathway. Nat Med 11:71-76

Jiang $Y$, Ortega-Molina A, Geng H, Ying HY, Hatzi K, Parsa S, McNally D, Wang L, Doane AS, Agirre $X$ et al (2017) CREBBP 
inactivation promotes the development of HDAC3-dependent lymphomas. Cancer Discov 7:38-53

Johnson NA, Boyle M, Bashashati A, Leach S, Brooks-Wilson A, Sehn LH, Chhanabhai M, Brinkman RR, Connors JM, Weng AP et al (2009) Diffuse large B-cell lymphoma: reduced CD20 expression is associated with an inferior survival. Blood 113:3773-3780

Khodadoust MS, Olsson N, Chen B, Sworder B, Shree T, Liu CL, Zhang L, Czerwinski DK, Davis MM, Levy R et al (2019) B-cell lymphomas present immunoglobulin neoantigens. Blood 133:878-881

Khodadoust MS, Olsson N, Wagar LE, Haabeth OA, Chen B, Swaminathan K, Rawson K, Liu CL, Steiner D, Lund P et al (2017) Antigen presentation profiling reveals recognition of lymphoma immunoglobulin neoantigens. Nature 543:723-727

Kim K, Skora AD, Li Z, Liu Q, Tam AJ, Blosser RL, Diaz LA Jr, Papadopoulos N, Kinzler KW, Vogelstein B et al (2014) Eradication of metastatic mouse cancers resistant to immune checkpoint blockade by suppression of myeloid-derived cells. Proc Natl Acad Sci USA 111:11774-11779

Klein JM, Henke A, Sauer M, Bessler M, Reiners KS, Engert A, Hansen HP, von Strandmann EP (2013) The histone deacetylase inhibitor LBH589 (panobinostat) modulates the crosstalk of lymphocytes with Hodgkin lymphoma cell lines. PLoS ONE 8: e79502

Kroesen M, Gielen P, Brok IC, Armandari I, Hoogerbrugge PM, Adema GJ (2014) HDAC inhibitors and immunotherapy; a double edged sword? Oncotarget 5:6558-6572

Kuppers R (2005) Mechanisms of B-cell lymphoma pathogenesis. Nat Rev Cancer 5:251-262

Lee SH, Yoo C, Im S, Jung JH, Choi HJ, Yoo J (2014) Expression of histone deacetylases in diffuse large B-cell lymphoma and its clinical significance. Int J Med Sci 11:994-1000

Liu X, Phillips AJ, Ungermannova D, Nasveschuk CG, Zhang G (2013). Macrocyclic compounds useful as inhibitors of histone deacetylases. US Patent 20130203681A1 (US Patent 20130203681A1.)

Lucas DM, Davis ME, Parthun MR, Mone AP, Kitada S, Cunningham KD, Flax EL, Wickham J, Reed JC, Byrd JC et al (2004) The histone deacetylase inhibitor MS-275 induces caspase-dependent apoptosis in B-cell chronic lymphocytic leukemia cells. Leukemia 18:1207-1214

Maloney DG (2012) Anti-CD20 antibody therapy for B-cell lymphomas. N Engl J Med 367:878-878

McCaw TR, Randall TD, Forero A, Buchsbaum DJ (2017) Modulation of antitumor immunity with histone deacetylase inhibitors. Immunotherapy 9:1359-1372

Merryman RW, Armand P, Wright KT, Rodig SJ (2017) Checkpoint blockade in Hodgkin and non-Hodgkin lymphoma. Blood Adv 1:2643-2654

Moreira JM, Scheipers P, Sorensen P (2003) The histone deacetylase inhibitor Trichostatin A modulates CD4+ T cell responses. BMC Cancer 3:30

Muramatsu M, Kinoshita K, Fagarasan S, Yamada S, Shinkai Y, Honjo T (2000) Class switch recombination and hypermutation require activation-induced cytidine deaminase (AID), a potential RNA editing enzyme. Cell 102:553-563
Murphy K, Weaver C (2017) Janeway's immunobiology, 9th edn. Garland Science, New York, pp 1-904

Nakata S, Yoshida T, Horinaka M, Shiraishi T, Wakada M, Sakai T (2004) Histone deacetylase inhibitors upregulate death receptor 5/TRAIL-R2 and sensitize apoptosis induced by TRAIL/APO2-L in human malignant tumor cells. Oncogene 23:6261-6271

Nijland M, Veenstra RN, Visser L, Xu CH, Kushekhar K, van Imhoff GW, Kluin PM, van den Berg A, Diepstra A (2017) HLA dependent immune escape mechanisms in B-cell lymphomas: Implications for immune checkpoint inhibitor therapy? Oncoimmunology 6:e1295202

Ok CY, Young KH (2017) Targeting the programmed death-1 pathway in lymphoid neoplasms. Cancer Treat Rev 54:99-109

Olejniczak SH, Stewart CC, Donohue K, Czuczman MS (2006) A quantitative exploration of surface antigen expression in common B-cell malignancies using flow cytometry. Immunol Invest 35:93114

Park JH, Riviere I, Gonen M, Wang X, Senechal B, Curran KJ, Sauter C, Wang Y, Santomasso B, Mead E et al (2018) Long-term follow-up of CD19 CAR therapy in acute lymphoblastic leukemia. N Engl J Med 378:449-459

Perez-Duran P, de Yebenes VG, Ramiro AR (2007) Oncogenic events triggered by AID, the adverse effect of antibody diversification. Carcinogenesis 28:2427-2433

Rimsza LM, Farinha P, Fuchs DA, Masoudi H, Connors JM, Gascoyne RD (2007) HLA-DR protein status predicts survival in patients with diffuse large B-cell lymphoma treated on the MACOP-B chemotherapy regimen. Leukemia Lymphoma 48:542-546

Rimsza LM, LeBlanc ML, Unger JM, Miller TP, Grogan TM, Persky DO, Martel RR, Sabalos CM, Seligmann B, Braziel RM et al (2008) Gene expression predicts overall survival in paraffinembedded tissues of diffuse large B-cell lymphoma treated with R-CHOP. Blood 112:3425-3433

Rimsza LM, Roberts RA, Miller TP, Unger JM, LeBlanc M, Braziel RM, Weisenberger DD, Chan WC, Muller-Hermelink HK, Jaffe ES et al (2004) Loss of MHC class II gene and protein expression in diffuse large B-cell lymphoma is related to decreased tumor immunosurveillance and poor patient survival regardless of other prognostic factors: a follow-up study from the Leukemia and Lymphoma Molecular Profiling Project. Blood 103:4251-4258

Roberts RA, Wright G, Rosenwald AR, Jaramillo MA, Grogan TM, Miller TP, Frutiger Y, Chan WC, Gascoyne RD, Ott G et al (2006) Loss of major histocompatibility class II gene and protein expression in primary mediastinal large B-cell lymphoma is highly coordinated and related to poor patient survival. Blood 108:311-318

Roemer MGM, Advani RH, Redd RA, Pinkus GS, Natkunam Y, Ligon AH, Connelly CF, Pak CJ, Carey CD, Daadi SE et al (2016) Classical Hodgkin Lymphoma with reduced beta M-2/MHC class I expression is associated with inferior outcome independent of 9p24.1 status. Cancer Immunol Res 4:910-916

Ropero S, Esteller M (2007) The role of histone deacetylases (HDACs) in human cancer. Mol Oncol 1:19-25

Rosborough BR, Castellaneta A, Natarajan S, Thomson AW, Turnquist HR (2012) Histone deacetylase inhibition facilitates 
GM-CSF-mediated expansion of myeloid-derived suppressor cells in vitro and in vivo. J Leukoc Biol 91:701-709

Rosenwald A, Wright G, Chan WC, Connors JM, Campo E, Fisher RI, Gascoyne RD, Muller-Hermelink HK, Smeland EB, Staudt LM et al (2002) The use of molecular profiling to predict survival after chemotherapy for diffuse large-B-cell lymphoma. N Engl J Med 346:1937-1947

Roussel M, Irish JM, Menard C, Lhomme F, Tarte K, Fest T (2017) Regulatory myeloid cells: an underexplored continent in B-cell lymphomas. Cancer Immunol Immunother 66:1103-1111

Sahakian E, Powers JJ, Chen J, Deng SL, Cheng F, Distler A, Woods DM, Rock-Klotz J, Sodre AL, Youn JI et al (2015) Histone deacetylase 11: A novel epigenetic regulator of myeloid derived suppressor cell expansion and function. Mol Immunol 63:579585

Scott DW, Gascoyne RD (2014) The tumour microenvironment in B cell lymphomas. Nat Rev Cancer 14:517-534

Serafini P, Mgebroff S, Noonan K, Borrello I (2008) Myeloid-derived suppressor cells promote cross-tolerance in B-cell lymphoma by expanding regulatory T cells. Cancer Res 68:5439-5449

Sermer D, Pasqualucci L, Wendel HG, Melnick A, Younes A (2019) Emerging epigenetic-modulating therapies in lymphoma. Nat Rev Clin Oncol 16:494-507

Shah NN, Maatman T, Hari P, Johnson B (2019) Multi Targeted CART Cell Therapies for B-Cell Malignancies. Front Oncol 9:146

Shalabi H, Kraft IL, Wang HW, Yuan CM, Yates B, Delbrook C, Zimbelman JD, Giller R, Stetler-Stevenson M, Jaffe ES et al (2018) Sequential loss of tumor surface antigens following chimeric antigen receptor T-cell therapies in diffuse large B-cell lymphoma. Haematologica 103:e215-e218

Sharma P, Hu-Lieskovan S, Wargo JA, Ribas A (2017) Primary, adaptive, and acquired resistance to cancer immunotherapy. Cell 168:707-723

Shimizu R, Kikuchi J, Wada T, Ozawa K, Kano Y, Furukawa Y (2010) HDAC inhibitors augment cytotoxic activity of rituximab by upregulating CD20 expression on lymphoma cells. Leukemia 24:1760-1768

Smahel M (2017) PD-1/PD-L1 blockade therapy for tumors with downregulated MHC class I expression. Int J Mol Sci 18:1331

Tang HD, Liang Y, Anders RA, Taube JM, Qiu XY, Mulgaonkar A, Liu X, Harrington SM, Guo JY, Xin YC et al (2018) PD-L1 on host cells is essential for PD-L1 blockade-mediated tumor regression. $\mathrm{J}$ Clin Investig 128:580-588

Tao R, de Zoeten EF, Ozkaynak E, Chen C, Wang L, Porrett PM, Li B, Turka LA, Olson EN, Greene Ml et al (2007) Deacetylase inhibition promotes the generation and function of regulatory $T$ cells. Nat Med 13:1299-1307

Taori K, Paul VJ, Luesch H (2008) Structure and activity of largazole, a potent antiproliferative agent from the Floridian marine cyanobacterium Symploca sp. J Am Chem Soc 130:1806-1807

Thurn KT, Thomas S, Moore A, Munster PN (2011) Rational therapeutic combinations with histone deacetylase inhibitors for the treatment of cancer. Future Oncol 7:263-283

Tiper IV, Webb TJ (2016) Histone deacetylase inhibitors enhance CD1d-dependent NKT cell responses to lymphoma. Cancer Immunol Immunother 65:1411-1421
Torres-Collad AX, Jazirehi AR (2018) Overcoming resistance of human non-Hodgkin's lymphoma to CD19-CAR CTL therapy by celecoxib and histone deacetylase inhibitors. Cancers 10:200

Tsai PC, Hernandez-llizaliturri FJ, Bangia N, Olejniczak SH, Czuczman MS (2012) Regulation of CD20 in rituximab-resistant cell lines and B-cell non-Hodgkin lymphoma. Clin Cancer Res 18:1039-1050

Wang JH (2013) The role of activation-induced deaminase in antibody diversification and genomic instability. Immunol Res 55:287-297

Wang JH, Alt FW, Gostissa M, Datta A, Murphy M, Alimzhanov MB, Coakley KM, Rajewsky K, Manis JP, Yan CT (2008) Oncogenic transformation in the absence of Xrcc4 targets peripheral $B$ cells that have undergone editing and switching. J Exp Med 205:30793090

Wang JH, Gostissa M, Yan CT, Goff P, Hickernell T, Hansen E, Difilippantonio S, Wesemann DR, Zarrin AA, Rajewsky $\mathrm{K}$ et al (2009) Mechanisms promoting translocations in editing and switching peripheral B cells. Nature 460:231-U294

Wang XG, Waschke BC, Woolaver RA, Chen ZG, Zhang G, Piscopio AD, Liu XD, Wang JH (2019) Histone deacetylase inhibition sensitizes PD1 blockade-resistant B-cell lymphomas. Cancer Immunol Res 7:1318-1331

West AC, Mattarollo SR, Shortt J, Cluse LA, Christiansen AJ, Smyth MJ, Johnstone RW (2013) An intact immune system is required for the anticancer activities of histone deacetylase inhibitors. Cancer Res 73:7265-7276

Woods DM, Sodre AL, Sarnaik A, Sotomayor EM, Weber J (2015) Class I HDAC inhibition upregulates PD-1 ligands in melanoma and increases the efficacy of PD-1 blockade. Cancer Res 3:1375-1385

Xiao H, Jiao J, Wang L, O'Brien S, Newick K, Wang LC, Falkensammer E, Liu Y, Han R, Kapoor V et al (2016) HDAC5 controls the functions of Foxp3(+) T-regulatory and CD8(+) T cells. Int J Cancer 138:2477-2486

Xu-Monette ZY, Zhou J, Young KH (2018) PD-1 expression and clinical PD-1 blockade in B-cell lymphomas. Blood 131:68-83

Yi M, Qin S, Zhao W, Yu S, Chu Q, Wu K (2018) The role of neoantigen in immune checkpoint blockade therapy. Exp Hematol Oncol 7:28

Ying Y, Taori K, Kim H, Hong J, Luesch H (2008) Total synthesis and molecular target of largazole, a histone deacetylase inhibitor. J Am Chem Soc 130:8455-8459

Yoon S, Eom GH (2016) HDAC and HDAC inhibitor: from cancer to cardiovascular diseases. Chonnam Med J 52:1-11

Youn JI, Kumar V, Collazo M, Nefedova Y, Condamine T, Cheng P, Villagra A, Antonia S, McCaffrey JC, Fishman M et al (2013) Epigenetic silencing of retinoblastoma gene regulates pathologic differentiation of myeloid cells in cancer. Nat Immunol 14:211220

Zain J, O'Connor OA (2010) Targeting histone deacetyalses in the treatment of B- and T-cell malignancies. Invest New Drugs 28 (Suppl 1):S58-S78

Zhou H, Luo YL, Zhu S, Wang X, Zhao YN, Ou XJ, Zhang T, Ma XL (2018) The efficacy and safety of anti-CD19/CD20 chimeric antigen receptor- $T$ cells immunotherapy in relapsed or refractory B-cell malignancies: a meta-analysis. BMC Cancer 18:929 